\title{
Atração e penetração de Meloidogyne javanica e Heterodera glycines em raízes excisadas de soja
}

\author{
Attraction and penetration of Meloidogyne javanica and Heterodera glycines in excised soybean roots
}

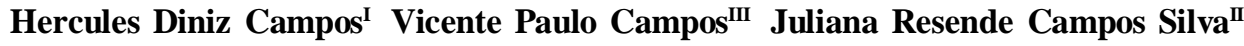 \\ Luiz Henrique Carregal Pereira da Silva ${ }^{\mathrm{II}}$ Lilian Simara Abreu Soares Costa ${ }^{\mathrm{II}^{*}}$ \\ Willian César Terra ${ }^{\mathrm{IV}}$
}

\section{RESUMO}

\begin{abstract}
Com vista ao estudo de atração e penetração de Meloidogyne javanica (Treub) Chitwood e Heterodera glycines (Ichinoe) em soja (Glycine max L.), desenvolveu-se uma técnica empregando-se segmento de raiz com $2 \mathrm{~cm}$ de comprimento. Nos segmentos de raiz de soja infectados, observou-se que a penetração de juvenis de segundo estádio $\left(J_{2}\right)$ de M. javanica ocorre pela coifa seguida de migração entre os feixes vasculares do cilindro central. Juvenis de $\boldsymbol{H}$. glycines penetraram, aproximadamente, $15 \mathrm{~mm}$ da coifa. A região seccionada da raiz de soja atraiu três vezes mais $\boldsymbol{J}_{2}$ de $\boldsymbol{M}$. javanica do que a região da coifa, mas esta não foi tão atrativa para $\mathrm{J}_{2}$ de $\boldsymbol{H}$. glycines. A obstrução conjunta da coifa e do local seccionado reduziu (83\%) a penetração de $J_{2}$, tanto de $\boldsymbol{M}$. javanica quanto de H. glycines. Quando apenas um desses locais foi obstruído, a outra extremidade livre compensou o processo atrativo. Portanto, as substâncias atrativas são liberadas por essas extremidades. A penetração de $J_{2}$ de M. javanica foi maior no segmento de raiz quando comparada com a plântula intacta de soja. Entretanto, os $J_{2}$ de $\boldsymbol{H}$. glycines penetraram menos em segmentos de raiz e em plântulas sem folhas, quando comparados com plântulas intactas e com as seccionadas no colo. Portanto, na cultivar de soja "Embrapa 20", a atração e os locais de penetração de $J_{2}$ de $\boldsymbol{H}$. glycines e M. javanica são diferenciados. Esta técnica poderá ser útil nos estudos de atração e penetração de outros nematoides endoparasitas.
\end{abstract}

Palavras-chave: nematoides, sistema radicular, plântulas, migração.

\section{ABSTRACT}

To study the attraction and penetration of Meloidogyne javanica (Treub) Chitwood and Heterodera glycines (Ichinoe) in soybean (Glycine max L.), a technique using $2-\mathrm{cm}$ long root segments was developed. In infected soybean root segments penetration of second stage juveniles $\left(\mathrm{J}_{2}\right)$ of M. javanica occured through the root cap following migration between the vascular bundles of the central cylinder. Juveniles of $\boldsymbol{H}$. glycines penetrated about $15 \mathrm{~mm}$ from the root cap. The cut region of the soybean root attracted three times more $J_{2}$ of $\boldsymbol{M}$. javanica when compared to the root cap, but was not as attractive to $\boldsymbol{H}$. glycines $J_{2}$. Sealing both root cap and cut region reduced $(83 \%)$ the $J_{2}$ penetration of $\boldsymbol{M}$. javanica and $\boldsymbol{H}$. glycines. When only one of these penetration sites was sealed the open site compensated attractiveness. These results show that the attractive substances are released by these two penetration sites. The M. javanica $J_{2}$ penetration was higher in root segments when compared to whole soybean plants. However, $\boldsymbol{H}$. glycines $J_{2}$ penetrated less in root segments and in roots of seedlings without leaves when compared to roots of whole soybean plants and roots of plants without the aerial part. In short, attraction and infection sites of $\boldsymbol{H}$. glycines and M. javanica $\mathrm{J}_{2} \mathrm{~s}$ in soybean cultivar "Embrapa 20 " are different and this technique may be useful in studies of attraction and penetration of other endoparasitic nematodes.

Key words: nematodes, root, seedlings, migration.

\section{INTRODUÇÃO}

O processo de penetração dos juvenis de segundo estádio $\left(\mathrm{J}_{2}\right)$ de Meloidogyne spp. e de Heterodera glycines (Ichinoe) em raízes de soja têm sido descrito por vários autores (ENDO, 1971;

'Fundação do Ensino Superior de Rio Verde, Rio Verde, GO, Brasil.

IIPesquisa e Tecnologia Ltda, Campos Carregal, Rio Verde, GO, Brasil.

IIIDepartamento de Fitopatologia, Universidade Federal de Lavras (UFLA), CP 3037, 37200-000 Lavras, MG, Brasil. E-mail:

lilianufla@yahoo.com.br. *Autor para correspondência.

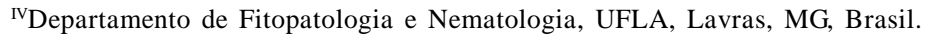


WALLACE, 1973; PROT, 1980; GRUNDLER \& WYSS, 1995; HUSSEY \& GRUNDLER, 1998; HUSSEY \& WILLIAMSON, 1998), mas a partir de observações com poucas evidências experimentais. Meios alternativos de como ocorre a penetração desses $\mathbf{J}_{2}$ foram sugeridos em alguns estudos (WIESER 1955, 1956; PROT, 1980; LEWIS, 1987). Da mesma forma, ainda se tem dúvidas sobre a possibilidade de penetração do $\mathrm{J}_{2}$ pela coifa ou através de tecidos laterais da raiz. Outro aspecto obscuro é a possibilidade do $\mathrm{J}_{2}$ penetrar em raízes com perda da extremidade e presença de tecido meristemático.

Estudos em que a penetração do $J_{2}$ é observada no sistema radicular como um todo tornam difícil a interpretação dos resultados. Ao contrário, a utilização de um único segmento de raiz facilita o acompanhamento do $\mathrm{J}_{2}$ no interior da raiz e permite observar um maior número de indivíduos por local de penetração. Assim, tem-se maior segurança na interpretação dos resultados. Entretanto, em alguns patossistemas, a técnica do uso de segmentos únicos de raiz para estudar a penetração do nematoide ainda precisa ser validada e/ou aprimorada. Dessa forma, o presente trabalho teve como objetivo desenvolver metodologia apropriada, empregando segmentos de raiz para descrever o processo de penetração e migração de $\mathrm{J}_{2}$ de Meloidogyne javanica (Treub) Chitwood e de H. glycines em plantas de soja.

\section{MATERIAL E MÉTODOS}

Preparo do inoculo

Para a obtenção do inoculo, populações puras de M. javanica e de H. glycines raça 3, mantidas em casa de vegetação da Universidade Federal de Lavras (UFLA - Lavras, MG), foram multiplicadas, separadamente, na cultivar de soja "Embrapa 20" (Doko RC) durante 30 (H. glycines) ou 50 (M.javanica) dias. Decorridos esses períodos, as raízes das plantas foram retiradas dos vasos e os ovos extraídos utilizando-se as técnicas de HUSSEY \& BARKER (1973) ( $\boldsymbol{M}$. javanica) e de DIAS et al. (1999) (H. glycines). Para a obtenção dos $\mathrm{J}_{2}$, a suspensão de ovos foi colocada em câmara de eclosão e mantida à temperatura de $26 \pm 2^{\circ} \mathrm{C}$. Nas inoculações, foram utilizados apenas os $\mathbf{J}_{2}$ que eclodiram após 72 horas, calibrando-se as suspensões para conterem $100 \mathrm{~J}_{2} \mathrm{~mL}^{-1}$.

Obtenção dos segmentos de raiz de soja

Sementes de soja "Embrapa 20", previamente desinfestadas superficialmente com solução de hipoclorito de sódio (1\%) por um minuto, foram colocadas para germinar em bandejas de plástico contendo areia grossa umedecida, mantidas em sala climatizada a $27 \pm 2^{\circ} \mathrm{C}$. Para a obtenção dos segmentos de raiz, após oito dias, radículas normais e com bom crescimento foram seccionadas, a $2 \mathrm{~cm}$ da coifa e transferidas para água, para evitar desidratação.

\section{Experimentos}

Estudos sobre penetração, migração e local de parasitismo do $\mathrm{J}_{2}$ de $\boldsymbol{M}$. javanica, em segmento de raiz de soja

O delineamento estatístico adotado foi o inteiramente casualizado com 18 tratamentos dispostos em esquema fatorial 3 (conjuntos de segmentos de raiz: um, dois ou três desses segmentos) x 6 (épocas de avaliação), com seis repetições. Conforme o tratamento, um, dois ou três segmentos de raiz foram retirados da água, transferidos para tubo de ensaio contendo $30 \mathrm{~cm}^{3}$ de areia fina quartizífera, previamente autoclavada a $120^{\circ} \mathrm{C}$ por 20 minutos, e inoculados com $100 \mathrm{~J}_{2}$ de $\boldsymbol{M}$. javanica. Após a inoculação, os tubos ficaram armazenados em sala climatizada para $27 \pm 2^{\circ} \mathrm{C}$ até o momento das avaliações. Nas avaliações, realizadas às $12,24,36,48,72$ e 96 horas seguintes à inoculação, os segmentos de raiz foram retirados dos tubos com o auxílio de jatos de água, lavados e submetidos a clareamento (hipoclorito de sódio a 1,5\%, durante 6 minutos). Uma vez enxaguados em água corrente para eliminar o resíduo de hipoclorito, os segmentos foram transferidos para tubos de vidro e, na sequência, eram cobertos com solução corante $(3,5 \mathrm{~g}$ de fucsina ácida + 250ml de ácido lático $+750 \mathrm{ml}$ de água destilada) diluída em água (1:29). Como proposto por BYRD et al. (1983), os segmentos permaneceram imersos na solução corante durante dois minutos, em banho-maria. Decorrido esse período, foram deixados resfriar, em condições ambientes durante uma noite e, após lavagem para retirar o excesso de corante, retornaram para os tubos. Em seguida, os segmentos foram cobertos com solução de glicerina 1:1 (glicerina pura + água destilada). Permaneceram em repouso nessa condição por, no mínimo, duas horas, quando teve início o preparo de lâminas para as observações sob microscópio ótico. Para a montagem das lâminas, os segmentos foram distribuídos sobre uma pequena gota de glicerina, dispersa entre duas lâminas de microscópio sobrepostas. Em cada uma das épocas de avaliação, foram quantificados os $\mathrm{J}_{2}$ presentes: 1) dentro do segmento de raiz; 2) na região de crescimento do segmento; e 3) na região do corte do mesmo segmento. Observaram-se, ainda, a orientação do $\mathrm{J}_{2}$ no processo interno de migração e os locais de penetração.

Efeito da posição do segmento de raiz de soja na penetração dos $\mathrm{J}_{2}$ de $\boldsymbol{M}$. javanica e de $\boldsymbol{H}$. glycines. 
O delineamento estatístico foi o inteiramente casualizado com quatro tratamentos, dispostos em esquema fatorial 2 (posições dos segmentos dentro dos tubos: para cima ou para baixo) x 2 (posições dos tubos na câmara de crescimento: horizontal ou verticalmente), com seis repetições. Para o estudo, segmentos de raiz de soja foram transferidos (um por recipiente), com a região do corte voltada para cima ou para baixo, para tubos de ensaio contendo $30 \mathrm{~cm}^{3}$ de areia fina quartizífera, previamente autoclavada a $120^{\circ} \mathrm{C}$ por 20 minutos e, em seguida, inoculados com $100 \mathrm{~J}_{2} \mathrm{de}$ M. javanica ou de $\boldsymbol{H}$. glycines. Após a inoculação, os tubos foram armazenados, na posição horizontal (50\%) ou vertical (50\%), em câmara de crescimento, ajustada para $27 \pm 2^{\circ} \mathrm{C}$. Decorridas 72 horas, os segmentos de raízes foram retirados dos tubos e submetidos aos mesmos procedimentos adotados no experimento 1 , quando do preparo das lâminas para as observações em microcópio ótico. No presente experimento, a avaliação consistiu na quantificação dos $\mathrm{J}_{2}$ de $\boldsymbol{M}$. Javanica ou de $\boldsymbol{H}$. glycines, nas regiões de crescimento e de corte do segmento, nas diferentes posições estudadas.

Efeito da obstrução das extremidades do segmento de raiz de soja na penetração dos $\mathrm{J}_{2}$ de $\boldsymbol{M}$. javanica e de H. glycines.

O delineamento estatístico utilizado foi o inteiramente casualizado com quatro tratamentos e seis repetições. Foram estudados três tipos de obstrução no segmento de raiz de soja: 1) obstrução apenas da coifa; 2) obstrução apenas da região seccionada; e 3) obstrução das duas extremidades. Como testemunha, foram utilizados segmentos sem nenhuma obstrução. Para as obstruções, a coifa e/ou a região seccionada do segmento de raiz foram imersas em parafina, numa extensão de $3 \mathrm{~mm}$. Após esses tratamentos (exceto no caso da testemunha), os segmentos foram transferidos (um por recipiente) para tubos de ensaio contendo areia quartizífera, previamente autoclavada a $120^{\circ} \mathrm{C}$ por 20 minutos, e, na sequência, inoculados com $100 \mathrm{~J}_{2}$ de $\boldsymbol{M}$. javanica ou de $\boldsymbol{H}$. glycines. Após a inoculação, os tubos foram armazenados em câmara de crescimento, ajustada para $27 \pm 2^{\circ} \mathrm{C}$. Decorridas 72 horas, os segmentos de raízes foram retirados dos tubos e submetidos aos mesmos procedimentos adotados nos experimentos 1 e 2, quando do preparo das lâminas para as observações em microcópio ótico. Neste experimento, foram quantificados os $\mathrm{J}_{2}$ de $M$. Javanica ou de $\boldsymbol{H}$. glycines presentes na coifa e na região de corte do segmento de raiz.
Estudos sobre a penetração dos $\mathrm{J}_{2}$ de $\boldsymbol{M}$. javanica e de $\boldsymbol{H}$. glycines em segmentos de raízes e em plantas de soja intactas ou seccionadas.

Os segmentos de raiz foram obtidos a partir do seccionamento, a $2 \mathrm{~cm}$ da coifa, de radículas normais e com bom crescimento de plantas de soja "Embrapa 20", cultivadas em sala climatizada, em bandejas contendo areia grossa umedecida. Em outro tratamento, a parte aérea

da planta de soja foi eliminada na região do colo. Como testemunhas, utilizaram-se plântulas de soja normais, bem como plântulas sem folhas, porém com caulículo. Raízes, segmento de raiz e plântulas, sem folhas ou normal, foram transplantados para tubo contendo areia fina quartizífera. Em seguida, cada tubo recebeu $1,0 \mathrm{ml}$ de suspensão contendo $100 \mathrm{~J}_{2}$ de $\boldsymbol{M}$. javanica ou de $\boldsymbol{H}$. glycines e foi mantido em sala climatizada a $27 \pm 2^{\circ} \mathrm{C}$.

Em todos os ensaios, a análise de variância foi realizada com o auxílio do programa Sisvar e as médias foram comparadas pelo teste de Tukey a $5 \%$ de probabilidade, transformando-se previamente os dados relativos ao número total de $\mathrm{J}_{2}$ de $\boldsymbol{M}$. javanica e de $\boldsymbol{H}$. glycines em raiz de $(\mathrm{x}+0,5)$.

\section{RESULTADOS E DISCUSSÃO}

Nos segmentos de raiz de soja infectados, observou-se que a penetração de juvenis de segundo estádio $\left(\mathrm{J}_{2}\right)$ de $\boldsymbol{M}$. javanica ocorre pela coifa, seguida de migração (corpo paralelo aos feixes) entre os feixes vasculares do cilindro central (Figura 1A). Além disso, grande aglutinação de $\mathrm{J}_{2}$ de $\boldsymbol{M}$. javanica foi observada no local seccionado (Figura 1B). Para os $\mathbf{J}_{2}$ de $\boldsymbol{H}$. glycines, não ocorreu penetração na região meristemática e nem na coifa. Neste caso, os $\mathbf{J}_{2}$ aglutinaram-se a $15 \mathrm{~mm}$ da coifa, em cuja vizinhança observaram-se rupturas na epiderme evidenciando, assim, o local de penetração (Figura 1C).

Não houve interação significativa entre o tempo de penetração de $\mathrm{J}_{2}$ de $\mathrm{M}$. javanica em soja e o número de segmentos de raiz por tubo. Entretanto, maior $(\mathrm{P} \leq 0,05)$ número de $\mathrm{J}_{2}$ de $\mathrm{M}$. javanica penetrou pela coifa, até 72 horas após a inoculação. Na região seccionada, a penetração foi elevada nos períodos de 12,72 e $96 \mathrm{~h}$ e o número de $\mathrm{J}_{2}$ encontrado na região seccionada foi três vezes maior do que na coifa. Quando se somou o número de $\mathrm{J}_{2}$ encontrado nos dois locais (coifa e região seccionada), uma maior $(\mathrm{P} \leq 0,05)$ penetração ocorreu às $12 \mathrm{~h}$ e $72 \mathrm{~h}$ (Figura $2 \mathrm{~A})$.

Ao analisar o número total de $\mathrm{J}_{2}$ nos dois locais (coifa e região seccionada), nos tubos com um, dois ou três segmentos, observa-se que uma maior 


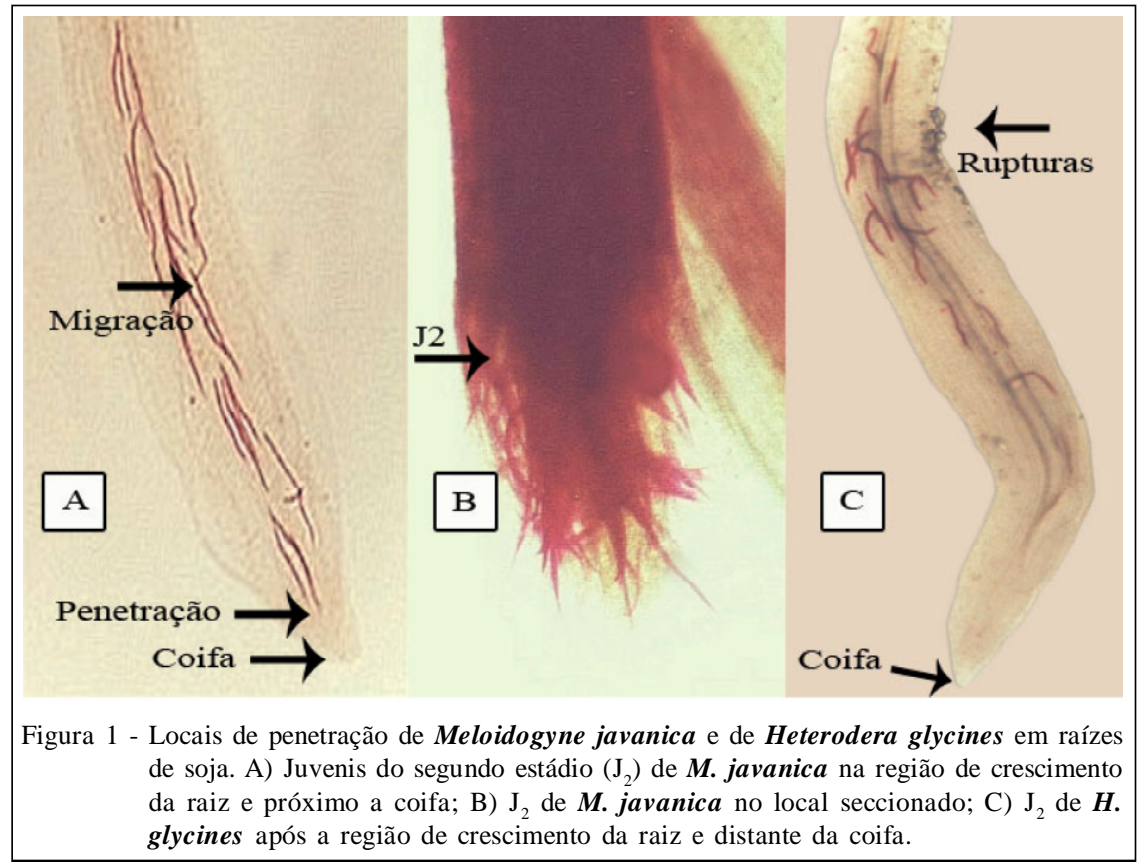

$(\mathrm{P} \leq 0,05)$ quantidade de $\mathrm{J}_{2}$ ocorreu nos tubos com apenas um segmento de raiz (Figura 2B). A colocação dos tubos com os segmentos de raiz na posição vertical possibilitou maior penetração de $\mathbf{J}_{2}$ na região de crescimento da raiz do que quando estes permaneceram na horizontal. Na região seccionada, a maior $(\mathrm{P} \leq 0,05)$ penetração de $\mathrm{J}_{2}$ ocorreu quando os tubos foram colocados na horizontal e a região do crescimento (coifa) estava voltada para a base do tubo. Mas, no total, menor $(\mathrm{P} \leq 0,05)$ número de $\mathrm{J}_{2}$ penetrou quando os tubos foram colocados na horizontal e região seccionada direcionada para a base do tubo. A penetração de $\mathrm{J}_{2}$ de $\boldsymbol{H}$. glycines no segmento de raiz foi mais baixa do que $\mathrm{J}_{2}$ de $\boldsymbol{M}$. javanica. Talvez por isso não tenha ocorrido diferença entre as formas de posicionamento dos tubos e dos segmentos para os $\mathbf{J}_{2}$ de H. glycines (Figura 2C).

Três milímetros de obstrução de qualquer região (coifa ou local seccionado) reduziram $\left(\mathrm{P}_{\leq} 0,05\right)$ a penetração de $\boldsymbol{M}$. javanica na extremidade obstruída. A penetração na região seccionada não obstruída foi sempre maior do que na região de crescimento. Mas o total de $\mathrm{J}_{2}$ de $\mathrm{M}$. javanica penetrado nas duas regiões só foi menor $(\mathrm{P} \leq 0,05)$ quando estas regiões foram, simultaneamente, obstruídas. Comportamento semelhante ocorreu no segmento de raízes inoculado com $\boldsymbol{H}$. glycines. Entretanto, a penetração de $\boldsymbol{H}$. glycines foi mais baixa do que a de $M$. javanica. A região seccionada não foi tão atrativa a $\mathbf{J}_{2}$ de $\boldsymbol{H}$. glycines quanto para os $\mathrm{J}_{2}$ de $M$. javanica (Figura 2D).
Quando se comparou a penetração de $\mathrm{J}_{2} \mathrm{em}$ segmentos de raiz de soja com planta, seccionada no colo, sem folha ou intacta, observou-se maior $(\mathrm{P} \leq 0,05)$ penetração de $\boldsymbol{M}$. javanica em segmentos de raiz do que na planta intacta. Contudo, maior $(\mathrm{P} \leq 0,05)$ penetração de $\mathbf{J}_{2}$ de $\boldsymbol{H}$. glycines ocorreu em plantas de soja seccionadas na região do colo e em plantas intactas (Tabela 1).

A aglutinação dos $\mathrm{J}_{2}$ na região meristemática da raiz foi observada também para $\mathrm{J}_{2}$ de $\boldsymbol{M}$. naasi em raízes de trigo e aveia (SIDDIQUI, 1971) e $\mathbf{J}_{2}$ de $\boldsymbol{M}$. javanica e M. hapla em tomateiro (BIRD, 1959). No presente estudo, a maior atração de $\mathrm{J}_{2}$ de $M$. javanica pela região seccionada da raiz de soja (Figura $2 \mathrm{~A}$ ), possivelmente, indica que a secção dos vasos condutores de seiva extravasa maior quantidade de substâncias atrativas. Entretanto, não se estudou a natureza dessas substâncias e nem o sucesso do parasitismo dos $\mathrm{J}_{2}$ que penetraram na região seccionada. Segundo WIESER $(1955,1956)$, a penetração de $\mathbf{J}_{2}$ de M. hapla só ocorre em raízes intactas.

A maior penetração de $\mathrm{J}_{2}$ de $\boldsymbol{M}$. javanica $\mathrm{em}$ soja verificada nos tubos com apenas um segmento de raiz (Figura 2B), ao que tudo indica, deveu-se a um melhor direcionamento do $\mathrm{J}_{2}$. Por outro lado, dois ou mais segmentos alteram esse direcionamento pelo efeito, talvez, de substâncias antagônicas ou até mesmo pela concentração da própria substância atrativa, que, em grandes quantidades, torna-se tóxica ou afeta temporariamente a mobilidade do $\mathrm{J}_{2}$. ZHAO et al. (2000) 


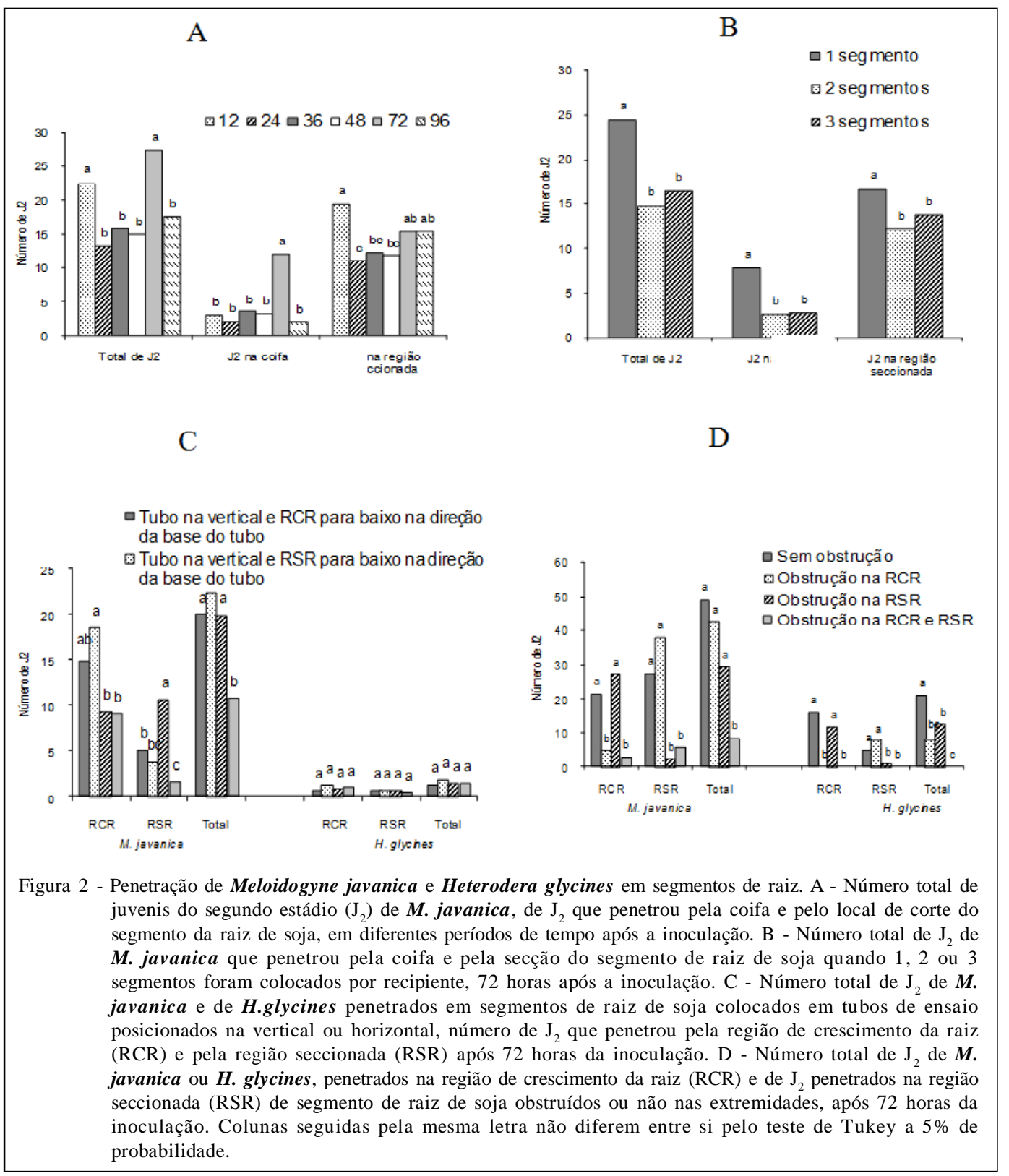

observaram imobilidade em $80 \%$ dos $\mathrm{J}_{2}$ de $\boldsymbol{M}$. incognita, quando esses foram deixados em contato com exsudato de células de folhas de alfafa, feijão e ervilha. ROCHA et al. (2005) verificaram que o exsudato de soja causou redução na mobilidade e penetração de $\mathbf{J}_{2}$ de $\boldsymbol{M}$. incognita em raiz de soja.

A redução de $83 \%$ verificada na penetração de $\mathrm{J}_{2}$ de $\boldsymbol{M}$. javanica, devido à obstrução das duas extremidades do segmento (Figura 2D) permite afirmar o seguinte: 1) as substâncias atrativas são liberadas dessas extremidades e influenciam no direcionamento dos $\mathbf{J}_{2}$ para o local de penetração; 2) a obstrução de uma das extremidades resulta em aumento da penetração de $\mathrm{J}_{2}$ na outra extremidade; e 3 ) a penetração ocorre diretamente nas extremidades e raramente nas laterais do segmento. $O$ fato de a secção da raiz, a $2,0 \mathrm{~cm}$ da coifa, ter resultado em maior atração de $\mathbf{J}_{2}$ de $\boldsymbol{M}$. javanica, provavelmente deveu-se à ausência de exsudatos em raízes intactas. Nessas, o exsudato fica concentrado na coifa ou concentra-se em locais seccionados, daí a existência na raiz de zonas de repelência a nematoides(WIESER, 1955, 1956).

Fica evidente que o $\mathrm{J}_{2}$ de $\boldsymbol{H}$. glycines tem menor atração pelo exsudato, tanto emanado pela coifa 
Tabela 1 - Penetração de juvenis do segundo estádio $\left(\mathrm{J}_{2}\right)$ de Meloidogyne javanica ou de Heterodera glycines em segmento de raiz de soja, ou em planta de soja seccionada no colo, sem folhas e intacta.

\begin{tabular}{|c|c|c|}
\hline Tratamentos & Números de $\mathrm{J}_{2}$ de $M$. javanica* & Números de $\mathrm{J}_{2}$ de $\boldsymbol{H}$. glycines* \\
\hline Segmento de raiz & $50,83 \mathrm{a}$ & $5,33 \mathrm{~b}$ \\
\hline Planta sem folhas & $39,83 \mathrm{ab}$ & $8,00 \mathrm{~b}$ \\
\hline Seccionada na região do colo & $40,16 \mathrm{ab}$ & $13,50 \mathrm{a}$ \\
\hline intacta & $27,00 \mathrm{~b}$ & $16,00 \mathrm{a}$ \\
\hline CV\% & 26,41 & 28,69 \\
\hline
\end{tabular}

*Médias seguidas pela mesma letra na coluna, não diferem entre si pelo teste de Tukey a 5\% de probabilidade.

ou acumulado na região seccionada (Figura 2D), comparado com $\mathrm{J}_{2}$ de M. javanica. Seu hábito de parasitismo, isto é, penetração lateral (HUSSEY \& GRUNDLER, 1998) em vez de distal (GRUNDLER \& WYSS, 1995), como realizado por M. javanica, compensa tal ineficiência.

A maior penetração dos $\mathrm{J}_{2}$ de $\boldsymbol{M}$. javanica no segmento da raiz (Tabela 1), provavelmente, ocorreu devido ao direcionamento mais preciso desses para uma única fonte de atração. No sistema radicular intacto a diversidade de fontes de atração (pontas de raiz) pode confundir o direcionamento do $\mathrm{J}_{2}$. Por outro lado, maior número de locais de atração pode resultar na produção de substâncias, que em altas concentrações passam a serem tóxicas ao $\mathrm{J}_{2}$ de $\boldsymbol{M}$. javanica (ZHAO et al., 2000; CAMPOS et al., 2002; ROCHA et al. 2005). Possivelmente, esse efeito tóxico é menos relevante para o $\mathrm{J}_{2}$ de $\boldsymbol{H}$. glycines. (Tabela 1).

\section{CONCLUSÃO}

A penetração de $\boldsymbol{M}$. javanica ocorre pela coifa e a de $\boldsymbol{H}$. glycines através da região além do alongamento da raiz, a mais ou menos $15 \mathrm{~mm}$ da coifa. Existem grandes diferenças entre essas duas espécies de nematoides, com relação ao aspecto quantitativo da atração do $J_{2}$ para o local de penetração. Maior penetração de M. javanica ocorre no segmento de raiz, comparado com todo o sistema radicular. Raízes excisadas podem ser úteis em estudos de atração e penetração de outros nematoides endoparasitas.

\section{AGRADECIMENTOS}

Os autores são gratos ao Conselho Nacional de Desenvolvimento Científico e Tecnológico (CNPq), pelo auxílio financeiro através de bolsa de apoio financeiro.

\section{REFERÊNCIAS}

BIRD, A.F. The attractiveness of roots to plant parasitic nematodes Meloidogyne javanica and Meloidogyne hapla. Nematologica, Leiden, v.4, n.1, p.322-335, 1959. Disponível em: <http://www.ingentaconnect.com/content/brill/nem>. Acesso em: 20 set. 2007. doi: ISSN 0028-2596.
BYRD, D.W. et al. An improved technique for clearing and staining plant tissues for detection of nematodes. Journal of Nematology, Lawrence, v.15, n.1, p.142-143, 1983. Disponível em: <http://www.ncbi.nlm.nih.gov/pmc/articles/ PMC2618249/pdf/142.pdf $>$. Acesso em: 22 set. 2007. doi: ISSN 0022-300X.

CAMPOS, H.D. et al. Efeito de exsudato radicular de Brachiaria decumbens sobre a eclosão e mobilidade de juvenis do segundo estádio de Meloidogyne javanica. Fitopatologia Brasileira, Brasília, v.27, n.2, p.185-186, 2002. Disponível em: <http:// www. scielo.br/scielo.php? script $=$ sci_serial\&pid $=0100$ 4158\&lng=en\&nrm=iso>. Acesso em: 3 ago. 2007. doi: ISSN $0100-4158$

DIAS, W.P. et al. Distribuição de raças de Heterodera glycines no Brasil. In: SOCIEDADE BRASILEIRA DE NEMATOLOGIA (Ed.). O Nematóide de cisto da soja: a experiência brasileira. Jaboticabal: Artsingner, 1999. Cap.6, p.95-103.

ENDO, B.Y. Nematode-induced syncitia (giant cells). Hostparasite relatioships of Heteroderidae. In: ZUCKERMAN, B.M. et al. Plant parasitc nematodes. New York: Academic, 1971. Cap.2, p.91-117.

GRUNDLER, F.M.W.; WYSS, U. Strategies of root parasitsm by sedentary plant parasitc nematodes. In: KOHMOTO, K.et al. Pathogenesis and host specificity in plant diseases. Oxford: Elsevier Science, 1995. Cap.2, p.309-319.

HUSSEY, R.S.; BARKER, K.R. A comparison of methods for collecting inocula of Meloidogyne spp., including a new technique. Plant Disease Reporter, Saint Paul, v.57, n.2, p.1025-1028, 1973.

HUSSEY, R.S.; GRUNDLER, F.M.W. Nematode parasites of plant. In: PERRY, R.N.; WRIGHT, D.J. The physiology and biochemistry of free-living and plant-parasitc nematodes. New York: CABI, 1998. p.213-244.

HUSSEY, R.S.; WILLIAMSON, V.M. Physiological and molecular aspects of nematode parasitism. In: BARKER, K.R. etal. Plant and nematode interations. Hardcover: American Society of agronomy, 1998. p.87-108.

LEWIS, S.A. Nematode-plant compatibility. In: VEECH, J.A.; DICKSON, D.V. (Ed.). Vistas on nematology. Hyattsville, M.D.: Society of Nematologists, 1987. p.246-252.

PROT, J.C. Migration of plant parasitic nematodes towards plant roots. Revue de Nématologie, Montrouge Cedex, v.3, n.2, p.305-308, 1980. 
ROCHA, F.S. et al. Ação de exsudatos radiculares de plantas na eclosão, motilidade, mortalidade e penetração de juvenis de Meloidogyne incognita. Summa Phytopathologica, Botucatu, v.31, n.2, p.187-193, 2005. Disponível em: <http:/ /www.scielo.br/scielo.php? script=sci_serial\&pid=0 100 $5405 \& \mathrm{nrm}=\mathrm{iso} \& \mathrm{rep}=\& \operatorname{lng}=\mathrm{pt}>$. Acesso em: 3 ago. 2007. doi: ISSN 0100-5405.

SIDDIQUI, I.A. Comparative penetration and develpment of Meloidogyne naasi in wheat and oat roots. Nematologica, Leiden, v.17, p.566, 1971. Disponível em: <http:// www.ingentaconnect.com/content/brill/nem>. Acesso em: 20 set. 2007. doi: ISSN 0028-2596.

WALLACE, H.R. Nematode ecology and plant disease. New York: Crane, Russak \& Company, 1973. 228p.
WIESER, W. The attractiveness of plants to larvae of root nematodes. I. The effect of tomato seedlings and excised roots on Meloidogyne hapla Chitwood. Proceedings of the Helmintological Society, Wash, v.22, n.2, p.106-112, 1955.

WIESER, W. The attractiveness of plants to larvae of rootknot nematodes. II. The effect of excised bean, eggplant and soybean roots on Meloidogyne hapla Chitwood. Proceedings of the Helminthological Society, Wash, v.23, n.1, p.59-64, 1956.

ZHAO, X. et al. Species-dependent effects of border cell and root tip exudates on nematodes behavior. Phytopathology, Saint Paul, v.90, n.11, p.1239-1245, 2000. Disponível em: <http://apsjournals.apsnet.org/loi/phyto>. Acesso em: 24 ago. 2007. doi: ISSN 0031-949X . 